\title{
Design and Development of a Mobile Application for Teaching Triple Multiplication to Preschool Children
}

\author{
Mona Kouhi $^{1}$ (D) Mohsen Rahmani ${ }^{1}$ (D)
}

Received: 8 September 2021 / Accepted: 13 January 2022 / Published online: 10 February 2022

(c) The Author(s), under exclusive licence to Springer Nature Singapore Pte Ltd 2022

\begin{abstract}
Due to the difficult educational condition caused by the COVID-19 pandemic, the design and development of mobile phone apps and technologies for teaching and learning are being more considered. Moreover, technology-based infrastructure for the use of distance education is developing rapidly. In this paper, an Android application called Triangular App (TriApp) was designed for teaching multiplication to preschool children. This application uses the Triple Multiplication method in which three numbers (including two numbers, and the product of multiplication of these two numbers) are considered as a group. By repeating and memorizing this group, if any of the numbers are not displayed, the child can guess the missed number. With TriApp, in addition to multiplication, children can also learn division. There is a test and competition section in which the child receives points by giving the correct answers, which increases the children's desire to learn. To evaluate the effectiveness of the TriApp, two preschool children groups were examined in 10 days. The former learned multiplication using TriApp and the later learned it using the multiplication table (repeated additions). The results showed that during test, $100 \%$ of the children that used the TriApp could answer asked multiplications correctly and only 40-70\% of the children who were trained through multiplication table could answer asked multiplications correctly. Also, the children were satisfied $94 \%$ with the application, whereas, they were satisfied only $60 \%$ with the multiplication table. This mobile application was developed using Java programming language, Eclipse IDE, and SQLite database.
\end{abstract}

Keywords Mobile application · Mobile learning · Preschool education · Distance education and online learning · Multiplication

\section{Introduction}

Since computer technologies and programming play an important role in human life and the training process [29], there are numerous computer programs in various scientific fields which are applied as important tools in the process of learning and teaching and have created a very close relationship between users and computer programs [7]. By having a correct understanding of new technologies and applying them properly in educational fields [12], it is possible to

This article is part of the topical collection "Innovation and Technology for Smart Learning" guest edited by Lam-for Kwok, Junjie Shang, Shinichi Sato, and Richard Li.

Mona Kouhi

mona.kouhi@yahoo.com

1 Department of Computer Engineering, Arak University, Arak, Iran upgrade the educational system and use those technologies to create a new and more efficient approach to improve the quality of educational fields [13].

Computer programs provide a variety of methods for humans to improve the quality of education. These programs are based on various programming languages such as Java, C, Python, etc. [35]. There are several operating systems for developing smartphone applications such as Symbian, Windows Mobile, iOS and Android, etc. The Android operating system is one of the most widely used systems [19]. Today, most tablets and phones use Android as the operating system. It is open source and allows the developers and hardware manufacturers to make changes to the operating system's core software and also it has a lot of app stores such as Google Play [9].

Children are an important part of society; it is crucial to pay attention to their educational methods and not use any methods and applications to teach them [43]. Therefore, it 
is necessary to get help from psychologists to design more efficient educational methods that are suitable for children to teach them properly [30].

Multiplication, addition, subtraction, and division are the four elementary arithmetic [32]. In the old educational methods, school teachers taught multiplication as repeated addition. This means that multiplying two numbers is equal to adding one of them to itself to the number of times the second number [27]. For example, multiplying the numbers 3 and 4 is the addition of number 3 to itself four times. Thus, children had to learn addition before multiplication, and by repeating the addition, they could calculate the multiplication of the numbers. Since the most important goal of the multiplication table is to answer quickly to the multiplication of numbers, this old method reduces children's speed in answering. Therefore, to improve the educational system, psychological sciences and modern technologies must meet to create more effective and efficient methods for educating children [38].

In this paper, an Android application called Triangular App (TriApp) was designed and developed for preschool children to learn multiplication. This application uses an educational method called the Triple Multiplication (TM) method that was devised by psychologists [15] to teach multiplication to children even before they go to school and learn addition. This app has five sections which two of these sections are most important namely: Learn Multiplication (LM) and Test and Competition (TC) section. In the LM section, Based on the TM method, three shapes on three sides of a triangle were designed (as a Gestalt to look at three numbers as a group) which on each of them, the numbers 2-9 appear. The reason for this design is, children can look at these three numbers as a unit and keep them in their minds. Therefore, if one of these three numbers is not displayed, the child can identify the missing number without interruption. The multiply and equal signs in this design were fixed, because it allows children to pay attention only to these three numbers and not to pay attention to the math symbols, to learn the multiplication only through their visual power and mine. In the TC section, several tests were designed to measure children's learning, which this section has 10 questions, and children will receive points by giving correct answers. In each question, one of these 3 numbers is not displayed randomly and the children have to guess that number by visualizing the three numbers they memorized in the LM section. This application was developed using Java language programming because of its simplicity, userfriendliness, security, and object orientation [4], SQLite database because of its speed, simplicity, and efficiency for Android applications [23], and Eclipse IDE, because it is free, open source and easy to work with [41]. The developed application will stabilize multiplication in the child's mind and improve their virtualization. Moreover, using this application, children will be familiar with multiplication and then division even before knowing their concept.

In this paper, we present a mobile application to meet the following purposes:

1. Using a new and efficient way instead of traditional methods to teach multiplication to preschool children.

2. Learning multiplication using mobile phones remotely.

3. Stabilizing multiplication in the child's mind and improving their virtualization.

4. Familiarizing children with multiplication and then division, even before going to school and knowing their concepts.

This paper is organized as follows: In Sect. "Literature Review", the literature review is given. Section "Methodology" is about the methodology of the TriApp. Section "Results and Discussion" is about the results and discussion of this study. Finally, in Sect. "Conclusion", the paper is concluded.

\section{Literature Review}

With the advancement of technology, distance education has been possible for students [14]. Hence, the development of infrastructures based on smartphones and tablets application has been considered rapidly. In distance education, it is possible for teachers to easily teach lessons to students and monitor their learning process using technology [20]. Yabut et al. [44] have developed an educational game application to empower elementary students in learning math. Using their designed game, teachers can teach mathematics to students, monitor them, design questions, and give them grades. Nikolopoulou et al. [31] have investigated preschool teachers' practices regarding ICT-supported early language and mathematics learning. They concluded that digital technology has the potential to support children's classroom experiences, but it is important for teachers to carefully plan and articulate suitable learning tasks for children. Therefore, the use of ICT could effectively support the learning process, particularly in mathematics, and the educational development of children as a whole [11].

There is a term called flipped learning in which teachers make lessons available to students to be accessed wherever and whenever it is convenient for them [45]. This allows class time to be used for student activities, creative thinking, interpersonal skills, etc. [40, 42]. Baharum et al. [5] have shown the steps of designing a flipped learning application. Also, they have shown improvements for flipped learning apps in their studies, and finally, they tested the effectiveness of their designed mobile application using the Electro Encephalo Graphy. 
The touchscreen has positive effects on learning [34]. Preschoolers can learn from interactive gaming experiences on touchscreen devices [1]. Also, there is evidence that shows if these applications are used in the learning process properly, they enhance mathematical thinking [10] and also the positive effect on attitudes to mathematics learning and student motivation [6] in both preschool and primary school settings. Additionally, the touch interface of tablets and mobile applications was considered to be a major learning facilitator for children with learning disabilities. Tablets can be a suitable and efficient tool for educating children due to their features such as lightness, portability, touch screen, zoom capability, speakers, etc. [28]. Moreover, the swipe and touch actions required for touchscreen tablets eliminate the complex spatial knowledge required to associate actions with the mouse or keyboard to actions on the screen. These diminished cognitive demands should increase content attention and enhance better and faster learning with mobile tablet devices than desktop computers. There are five advantages to using tablets, such as portability, cost-effectiveness, accessibility everywhere, timely learning opportunities, connectivity, and convergence, etc. [39].

In 2020 and 2021, several mobile applications have been designed to teach mathematics to preschool children. Harahap et al. [18] have developed a Learning Media Platform for children based on the Android operating system which offered Indonesian and basic math lessons. Anwar et al. [3] have designed a mobile game to learn math to primary students. In their designed application, mathematics was taught along with playing the game. Amasha et al. [2] have developed a mobile application using the Java programming language for primary students to learn mathematics. Also, they concluded that students using mobile applications will have further improved learning mathematics, and these applications are more efficient than traditional methods. Gocheva et al. [17] have offered a game-based approach to learning through mobile games that can develop children's math skills and offer a fun environment where learning is easier and more fun even for children who do not like math. Kwok et al. [25] have introduced the use of game-based learning for children to learn simple arithmetic. They believed that artificial intelligence can be a good way to motivate children to learn simple arithmetic during gameplay.

All the applications mentioned above teach mathematics and multiplication to children using old methods (repeated addition and multiplication table), and there is no new application to teach multiplication that uses novel and efficient methods and helps children to learn multiplication by playing, even before going to school.

\section{Methodology}

\section{Triple Method}

The method used in this application was devised by Dr. Riazi-Farzad [15]. In his view, it is required to consider the multiplication table a "label" and not "the concept", and the children should repeat the results immediately, without understanding them. Because he believes that at this stage of learning, the children are not required to understand the concept of multiplication, because paying attention to the concept at this stage reduces their speed in answering and calculating, since the main reason for using multiplication table is to speed up the action. As children learn the names of geometric shapes regardless of their meanings in their childhood, they can learn the multiplication even before they learn the addition. Moreover, people can remember the poems and songs since their childhood, but if at that time they were considering them, they could not remember them as they had in the past. Based on these statements, Dr. Riazi-Farzad introduced a new multiplication method called Triple Multiplication (TM) [15], which is the basis of the developed application through this work.

\section{System Architecture}

The $4+1$ view model describes the architecture of software systems from the viewpoint of different stakeholders, such as developers, project managers, system engineers, end-user, etc. [24]. The proposed application architecture is expressed by the use of the $4+1$ view model.

\section{Use Case Diagram}

Use case diagram provides a better understanding of the application behavior [16]. It contains the required system functions and facilitates the understanding of the system scenario [8]. Use cases of the application components are given in Table 1, and the use case diagram of the application is shown in Fig. 1.

Table 1 Use cases of the TriApp

\begin{tabular}{ll}
\hline Components & Use cases \\
\hline User & Signs up \\
& Logs in \\
& Learns multiplication \\
& Takes a test \\
Admin & Updates the TC sec- \\
& tion \\
& Fixes application bugs \\
& Manages application \\
\hline
\end{tabular}




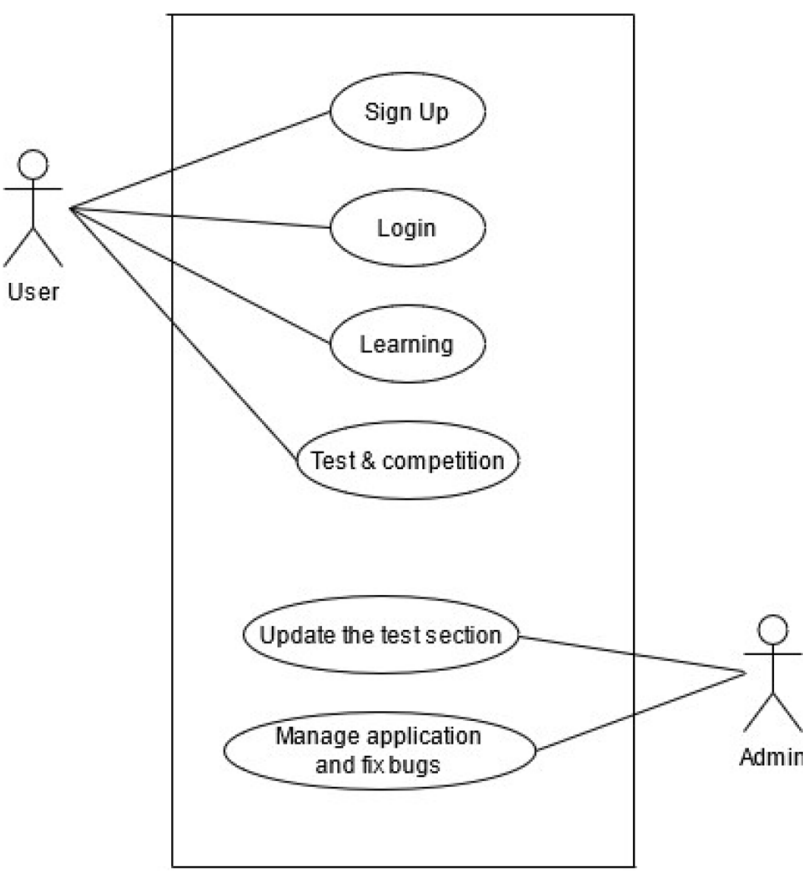

Fig. 1 Use case diagram of the TriApp

According to Table 1 and Fig. 1, there are two components in this application: the user component and the admin component. The users can register and log into the application and see the menu. Moreover, they can go to the LM section and start learning. Finally, they can enter the TC section and take the test and get points. The admin component manages and supports the application and fixes its bugs. Also, any updates on test questions can be done using admin.

\section{Class Diagram}

The class diagram shows the classes of the system, their relationships, and the operations and attributes of the classes [8]. Figure 2 shows the class diagram for the TriApp which has four database tables including User, User_log, Question, and Score. The tasks of each of them are shown in the following:

- User table: stores user information including the username, password, age, gender, and total score.

- User_log table: stores logs of all tables with the date and time.

- Question table: stores the questions of the TC section with the user level.

- Score table: stores user scores.

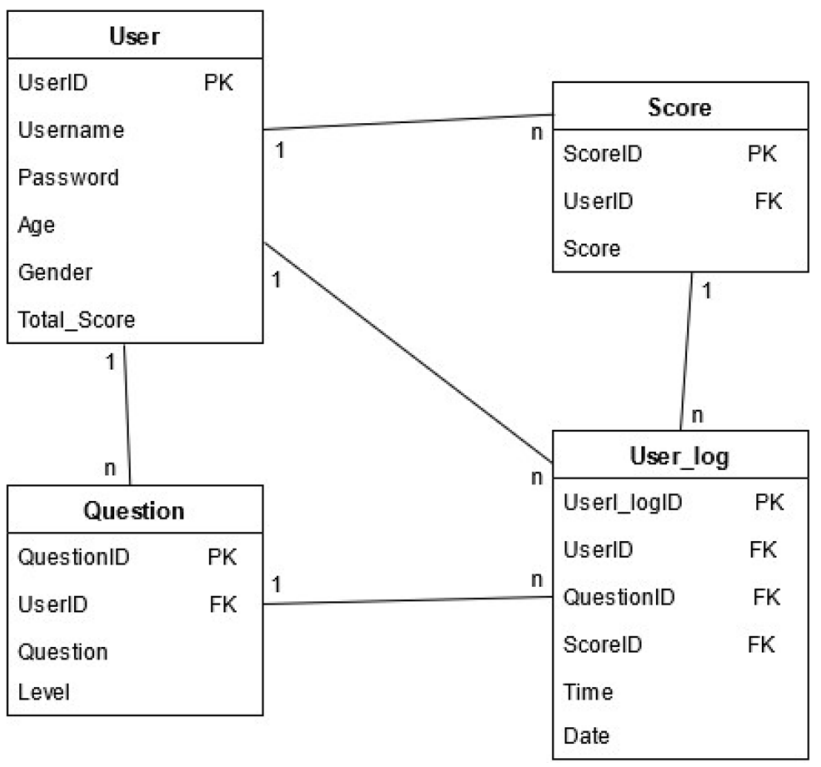

Fig. 2 Class diagram of the TriApp

\section{TriApp Features}

The TriApp has some features that distinguish it from other applications and other methods. In the following, these features are discussed in detail.

\section{Consider Three Numbers as a Group}

In this method of learning, three numbers are considered as a group that is arranged together. The name of this group is "Gestalt". The Gestalt allows three numbers to be stored in memory and their relationship can be remembered. When Gestalt is learned at the same time, all of its elements are memorized. For example, the result of the multiplication of numbers 8 and 9 is 72 , once 72 is said, two other numbers, 8 and 9, come to mind quickly. Different shapes are considered for a Gestalt as its sample is shown in Fig. 3.

To reach this goal, in this application, 8 different shapes were designed as the Gestalt for numbers $2-9$. These shapes

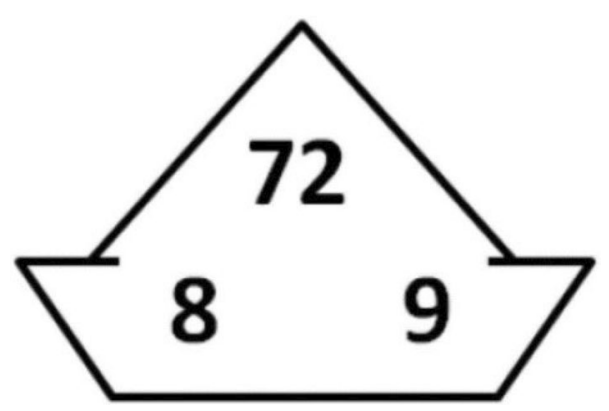

Fig. 3 A view of a Gestalt 
were considered as a triangle in which 2 numbers that want to be multiplied were located at the bottom of this triangle and in the left and right corners and their product was placed at the top of this triangle. The multiplication sign was fixed in these shapes, but the numbers changed. In Fig. 4, two of these shapes are shown.

\section{The Different Display of Numbers and Play the Sound of Numbers}

In this application, by entering the LM section and selecting one of the multiplies by 2-9 (Fig. 10c), and entering its page, the first number in the left corner appears with a delay of 2 s along with its specific sound (Fig. 5a). Then, the second number in the right corner appears two seconds after the first number with its specific sound (Fig. 5b). Finally, the product number appears $4 \mathrm{~s}$ after the second number with its specific sound (Fig. 5c). This different way of displaying numbers allows children to both learn the sound of the numbers and to keep the numbers better in their minds due to these delays in the display of the numbers. This feature both encourages

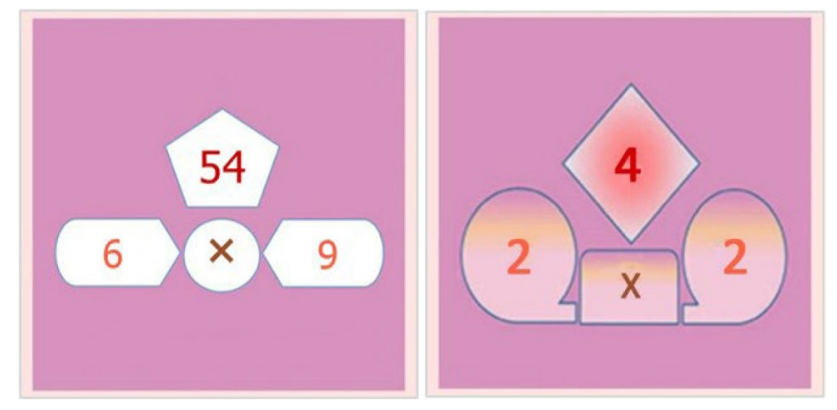

Fig. 4 Two examples of designed Gestalts for this application children to learn multiplication and makes children more attracted to use this application. Figure 6 shows the mentioned display method.

\section{Guess Three Numbers Randomly}

In the previous section, it was mentioned that teaching multiplication concepts using old methods reduces children's answering speed, and in most cases, multiplication was taught using the multiplication table. The problem with this method is that when children look at for example line 3 in Fig. 6, they find that the next numbers are

\begin{tabular}{|c|c|c|c|c|c|c|c|c|c|c|}
\hline$x$ & 1 & 2 & 3 & 4 & 5 & 6 & 7 & 8 & 9 & 10 \\
\hline 1 & 1 & 2 & & 4 & 5 & 0 & & 8 & 9 & 10 \\
\hline 2 & 2 & & 6 & 8 & 10 & 12 & 14 & & 18 & 20 \\
\hline 3 & & 6 & & 12 & 15 & 18 & 21 & 24 & 7 & 30 \\
\hline 4 & 4 & 8 & 12 & & 20 & 24 & 28 & 32 & & 40 \\
\hline 5 & 5 & 10 & 15 & 20 & & 30 & 35 & 40 & 4 & 50 \\
\hline 6 & & 12 & 18 & 24 & 30 & & 42 & 48 & 4 & 60 \\
\hline 7 & 1 & 14 & 21 & 28 & 35 & 42 & & 5 & 63 & 70 \\
\hline 8 & 8 & 1 & 24 & 32 & 40 & 48 & 5 & 64 & 72 & 80 \\
\hline 9 & 9 & 18 & 27 & 50 & & 54 & 63 & 72 & 81 & 90 \\
\hline 10 & 10 & 20 & 30 & 40 & 50 & 60 & 70 & 80 & 90 & 100 \\
\hline
\end{tabular}

Fig. 6 The old method of learning multiplication
Fig. 5 How to display numbers in the learning section
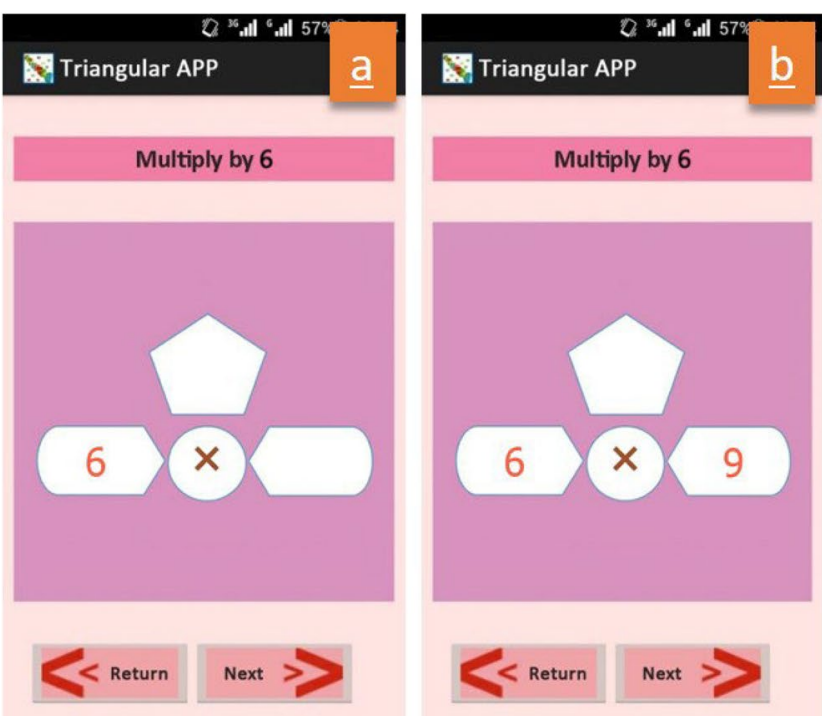
obtained by adding the product of the previous multiplication to 2 . Therefore, when the product of multiplication is asked of the child, he tries to use this pattern and find an answer that reduces their answering speed. Multiplication training should be done in a way that the child cannot find any pattern to answer the other multiplications. Regarding this, in the developed application, in the TC section, every three numbers were displayed and asked randomly from the child and the child needs to have learned all three numbers by repeating and remembering them in the LM section. Therefore, if one of them is not displayed in the question, the child can guess it. In Fig. 7, the child has to guess the product of multiplication of the numbers 4 and 6 and fill it in its place.

\section{Points and Awards}

Giving points to the users encourages them to learn and use the application more. Thus, in this application, the scoring system was used to enhance children's desire to learn. For this reason, for each correct answer, they are given points. Figure 8 shows the final score of the user. Also, Fig. 7 shows the correct answer point of a question with a message and a sign to show that the answer is correct.

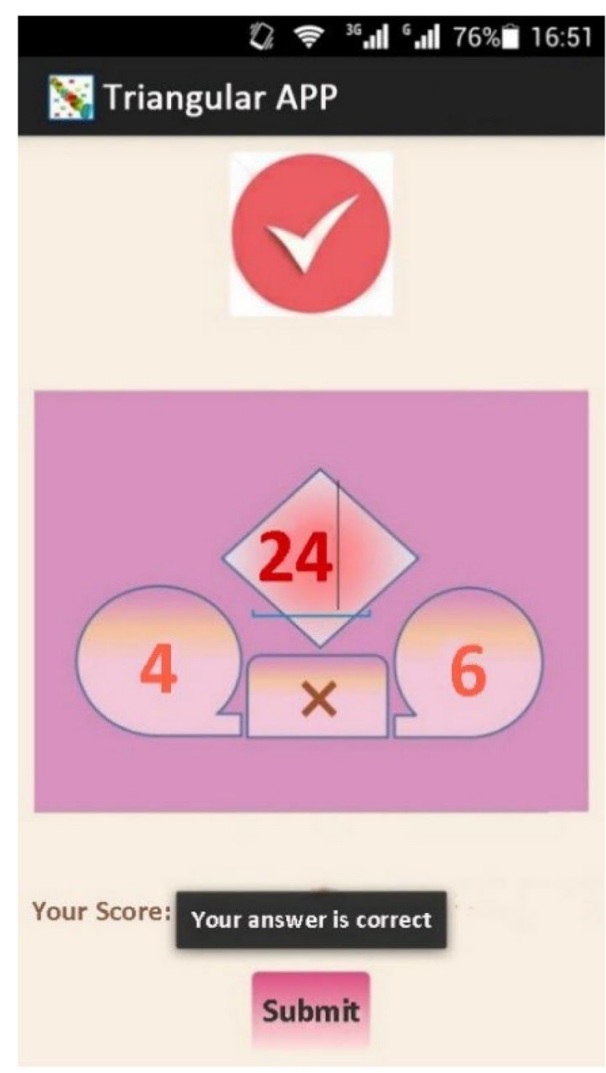

Fig. 7 Guess the numbers in the TC section

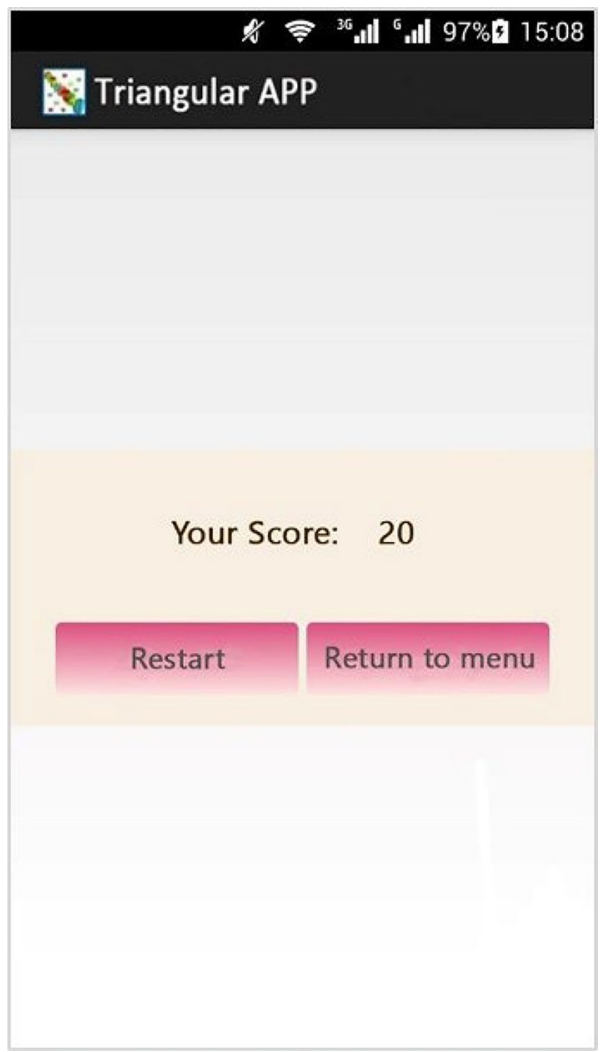

Fig. 8 The final score of the child

\section{The Relationship Between Three Numbers and Learning How to Divide}

In general, the unique format used to teach multiplication in this application is that it shows the relationship between three numbers regardless of mathematical symbols. Therefore, children can easily keep this relationship in their minds. This is another important feature of learning through this application. By knowing this relationship, children can easily learn division and quickly answer the division of numbers. Figure 9 shows the relationship between numbers.

According to Fig. 9, if we look up from the bottom, we can see two numbers that want to be multiplied by each other at the bottom and the product of this multiplication at the top of Fig. 9. Also, if we look down from the top, we can see the product of the multiplication of two numbers. If this number is divided by any of the two numbers on the bottom right or left, it gives the third number. This indicates that the child can learn division using this application, in addition to multiplication.

\section{The Multiplication Without Numbers 0 and 1}

In this application, there are no numbers 0 and 1 . Because multiplying each number by 1 will be the same number, and 


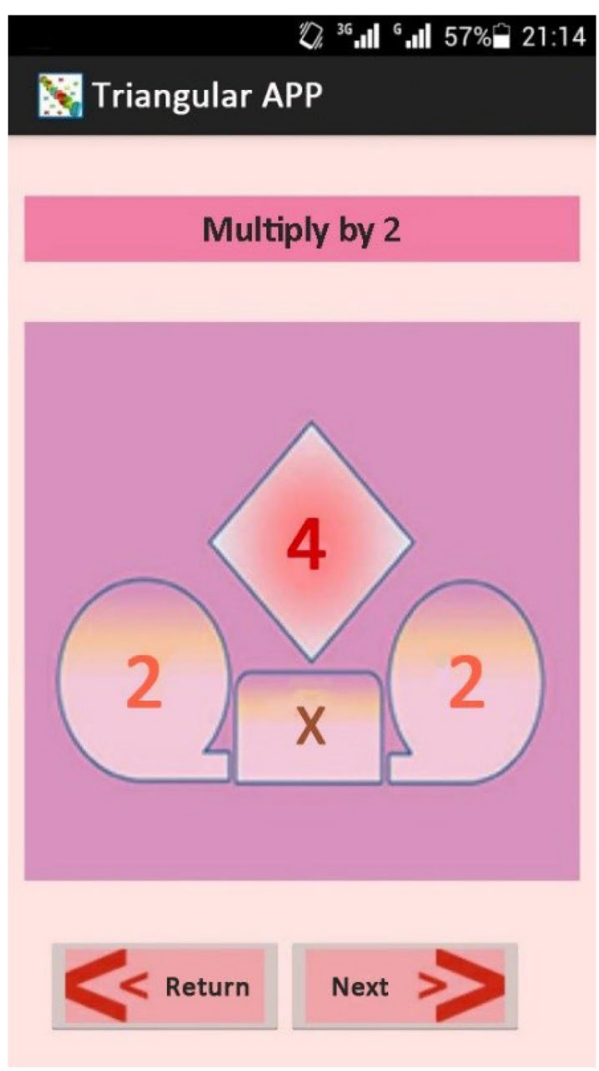

multiplying each number by 0 will be 0 , which is not very hard for children to learn. That is why, the numbers in this application start from 2 .

\section{TriApp User Interface}

The user interface of this application is designed in a way that in addition to simplicity, it is attractive for children to work with. To start working with this application, children must first register and then $\log$ in to the application (Fig. 10a). After entering the app, they will see five buttons (Fig. 10b). If they want to start learning, they should click on the LM section (Fig. 10c). In this section, they will see learning multiplication 2-9 and can click on anyone they want and start learning (Fig. 9). When the children have learned the multiplication of all of the numbers, they can go to the TC section to measure their learning and answer the questions that are asked by not displaying one of the numbers randomly and get points for their correct answers (Fig. 7).

Working with this application is very easy for children. They can learn, take tests, and get points easily using the right method. Currently, the TriApp is available on the Iranian Android marketplace called Cafe Bazaar [22].

Fig. 9 The relationship between numbers
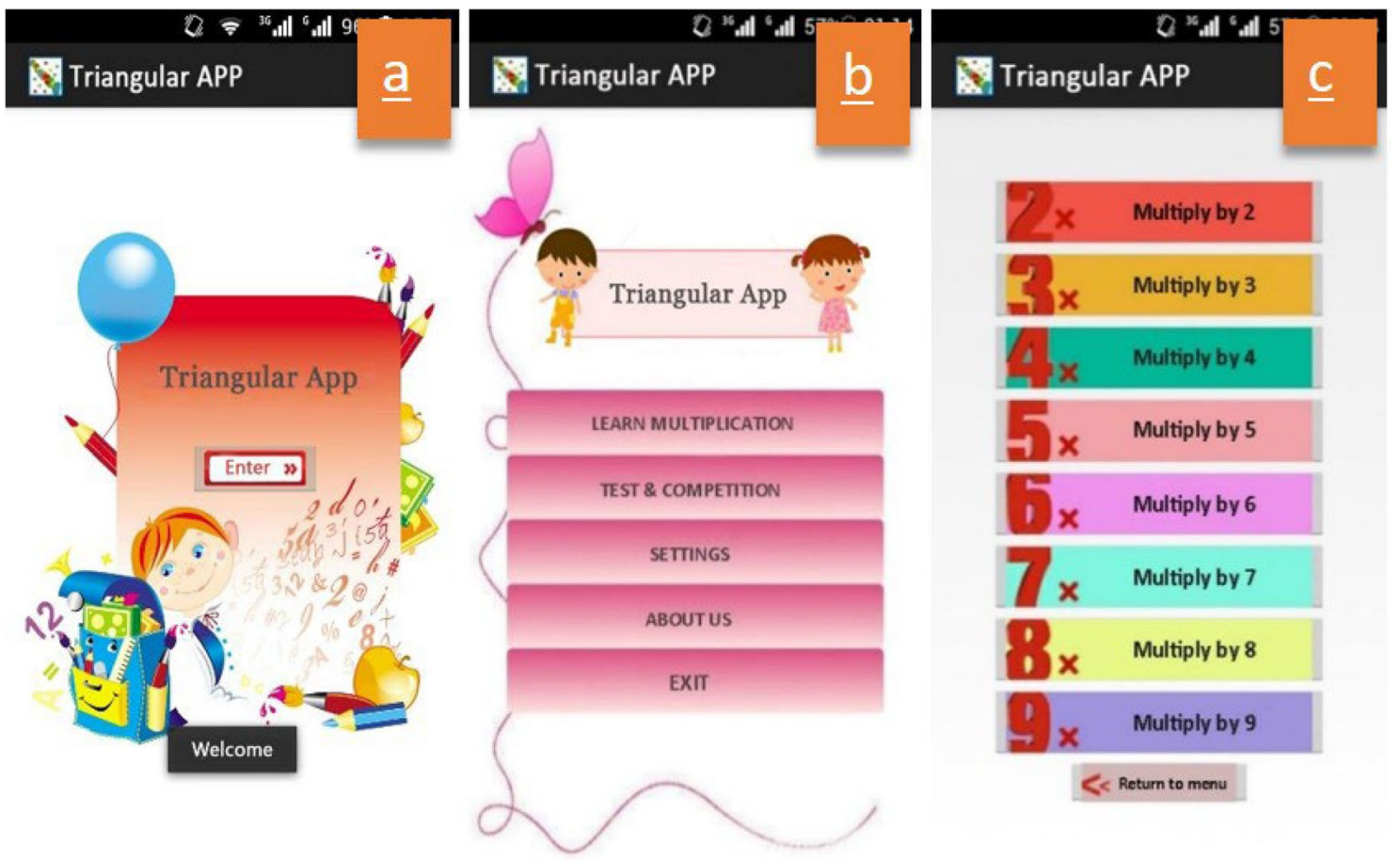

Fig. 10 a Start page, b menu, and c LM section 


\section{System Design}

To develop this application based on Android 8.0, version SE 9 of the Java programming language was used. The IDE used to develop this application was the Oxygen version of the Eclipse IDE. Moreover, for compiling the app, Android SDK with version 26.1.1 was downloaded and used [26]. Because it is not possible to execute an Android application on Windows, it is required to use an Android emulator. The Genymotion software was used as a virtual device to run the app on Windows [21].

In programming for the Android operating system using Java, there are 2 types of files: Activity file and layout file. The layout file deals with the user interface of the application and sets all the views that will be visible on the screen. Layout files are in XML format (.xml). Because it is a lightweight language. The activity file is a Java class that deals with the code and the layouts. Activity files are in java format (.java) [33]. In developing the TriApp, more than about 70 activity files and for each activity file, one layout file was programmed. Also, a database called TriangularDB was created using the SQLite database that was connected to the project.

The most important classes that were used to develop this app are MediaPlayer-PersianReshape-CountDownTimer. The MediaPlayer class was used to control the sounds of the numbers and play and stop them at specified times. The PersianReshape class was used to convert the language of the application to the Persian language. Finally, the CountDownTimer class was used to schedule the display of numbers on the screen. Delays in displaying numbers in the LM section were set by this class.

\section{Results and Discussion}

To evaluate the effectiveness of the TriApp, two preschool children groups were examined. The first group learned multiplication using TriApp and the second group learned it using the multiplication table (repeated additions). For the first group, the app was installed on 28 preschool children's parents' mobile phones with an average age of 4 years at Bahaar kindergarten in Iran. Before using this app, they had no idea about multiplication. Their parents were asked to encourage the children to use this application and work with it every day, and send us their feedback about the application for 10 days. For the second group, the multiplication table was taught to 28 preschool children at the same kindergarten. After about 10 days, all children's information was received and obtained the following results.

A. The Results of Using TriApp and Using the Multiplication Table

- Using the app, in the first 3 days, $80 \%$ of children had between 1 and 3 correct answers (out of 10 questions). In the next 4 days, they had between 4 and 8 correct answers. And finally, all of them (100\%) in 10 days were able to answer all of the questions correctly and get full points. Figure 11 shows the result of testing the app.

- According to Fig. 11, on days 1-3, 15 girls and 13 boys with an average age of 4 were learning using this app that they were able to answer between 1 and 3 questions (10$30 \%$ ) correctly. On days 4-7, 12 girls and 11 boys were learning using this app that this decrease in the number
Fig. 11 The results of using TriApp for 10 days
The results of using TriApp

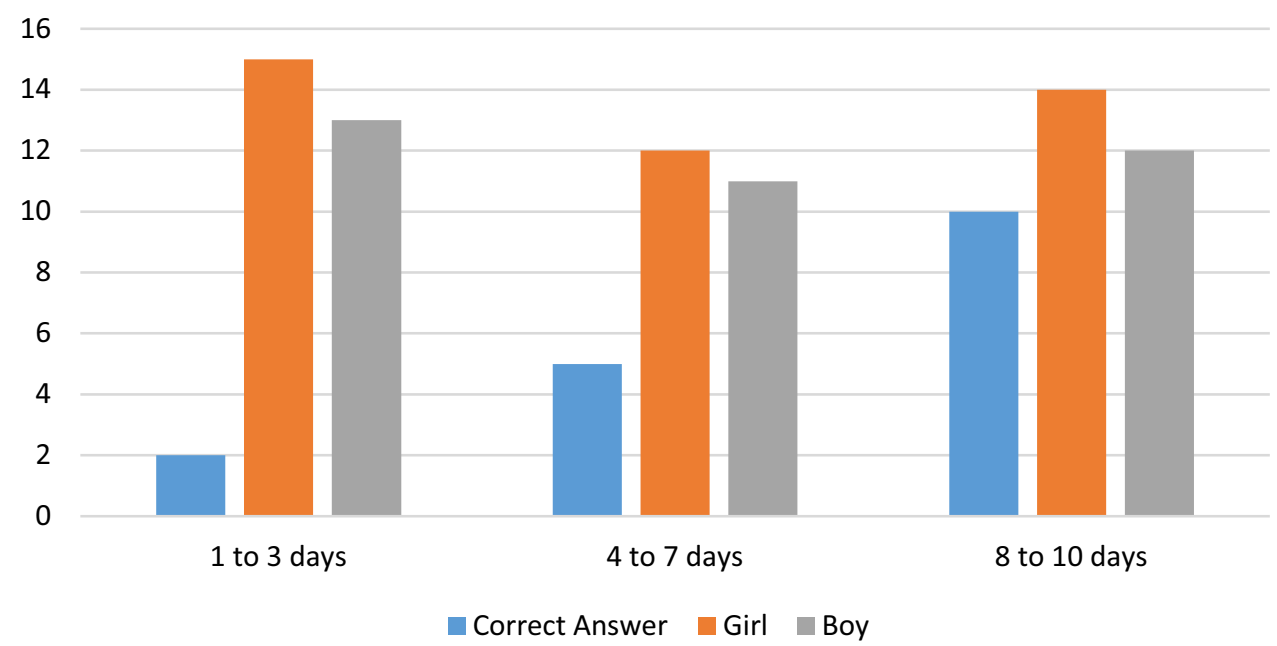


of children indicates that $18 \%$ of children have not used the app to learn for different reasons during these days, and they were able to answer between 4 and 8 questions (40-80\%) correctly. On days 8-10, 14 girls and 12 boys were learning using this application that this increase in the number of children represents a $12 \%$ increase in multiplication learning using this app that indicates children who did not use the app during days 4-7, returned to the app again and they were able to answer all 10 questions (100\%) correctly. Results showed that, after 10 days, children were able to learn multiplication completely only using this application and their memory, and without any mathematical and addition background or going to school.

- Using the multiplication table, in the first 3 days, $86 \%$ of children had between 1 and 3 correct answers (out of 10 questions). In the next 4 days, they had between 3 and 4 correct answers (30-40\%). And finally, in 10 days, they were able to answer between 4 and 7 questions (40-70\%) correctly. Figure 12 shows the result of testing the app.

According to Fig. 12, on days 1-3, 18 girls and 10 boys with an average age of 4 were learning using multiplication table that they were able to answer between 1 and 3 questions (10-30) correctly. On days 4-7, 15 girls and 9 boys were learning using the multiplication table that this decrease in the number of children indicates that $15 \%$ of children have tired of learning (or some other reasons) and have not continued during these days and they were able to answer between 3 and 4 questions (30-40\%) correctly. On days 8-10, 11 girls and 7 boys were learning using the multiplication table that this decrease again in the number of children indicates $25 \%$ of children have had reasons not to continue learning using multiplication table and they were able to answer between 4 and 7 questions (40-70\%) correctly.

The result of this comparison shows that using the TriApp, children can learn multiplication more effectively and in less time by playing.

\section{B. User Response}

The practical aspects of mobile application based on the TM method in this study were measured through student responses and student activities when participating in learning. The TriApp will be practical if user responses are positive and user activities are high. Figure 13 shows user response in 10 days.

According to Fig. 13, from day 1 to day 3, the user response was negative, but after day 4 , the users' satisfaction with working with the application and learning multiplication increased. On day 10, it reached nearly $90 \%$. This indicates that the application has received a positive response and users have satisfied with working with it.

\section{User Activity}

As it was mentioned in the previous section, if the user activities are high, it shows that the application is practical. During these 10 days, the activities of children in participating in learning multiplication with this mobile application based on the TM method have increased. Figure 14 shows user activity.

According to Fig. 14, the user activity from about five activities in the first days has increased to about 11 activities in the last days, which indicates the great interest of children and users of the application to work with the application. This also indicates that this application is practical.
Fig. 12 The results of using the multiplication table

\section{The results of using the multiplication table}

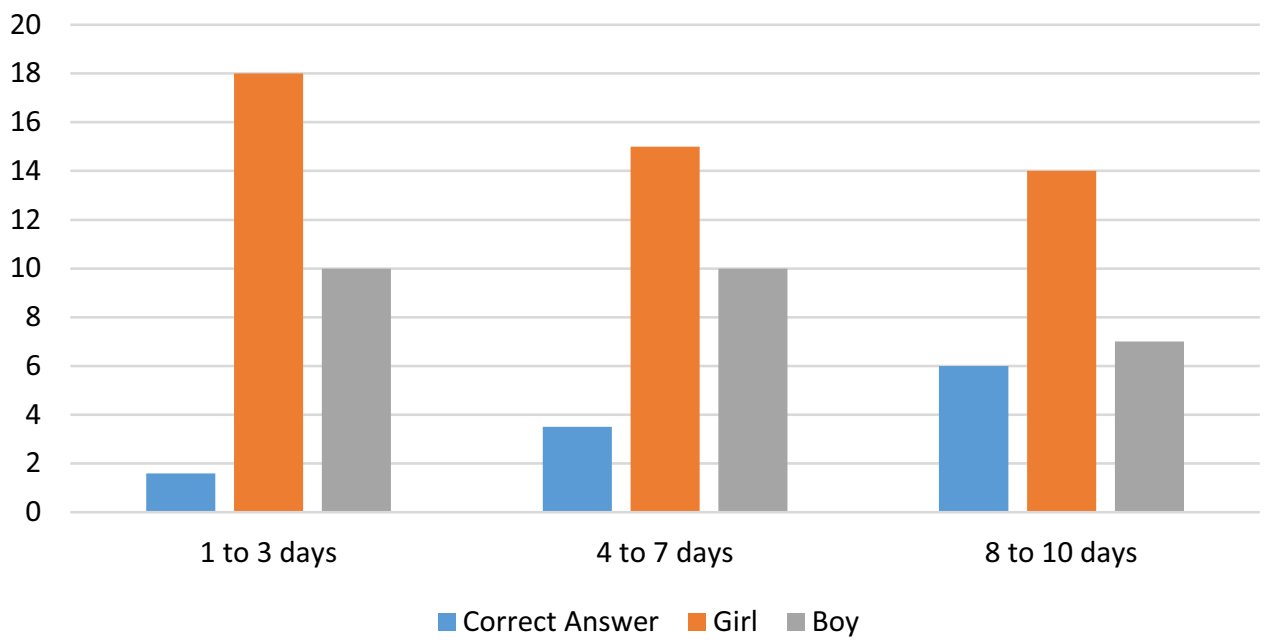


Fig. 13 User response

User Response

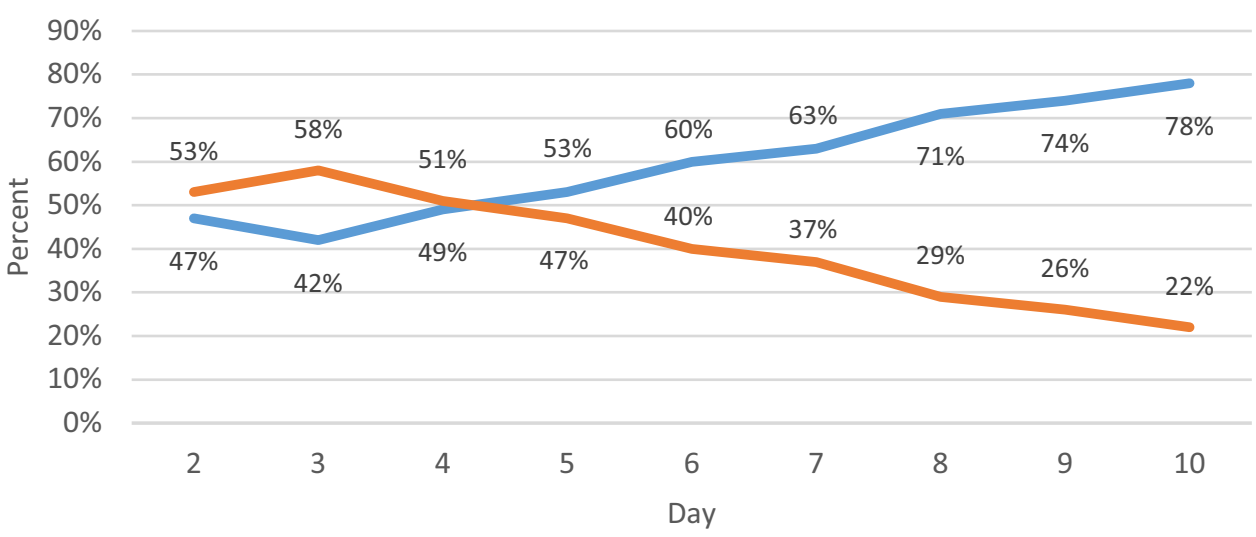

Positive Response $\longrightarrow$ Negative Response

Fig. 14 User activity

\section{User Activity}

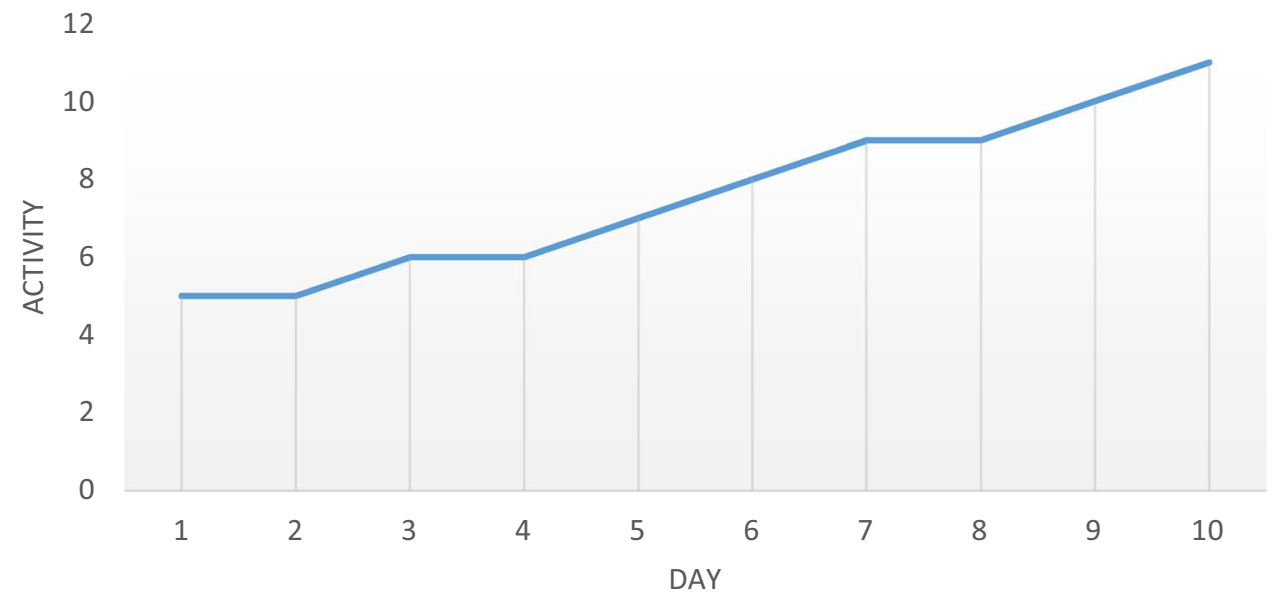

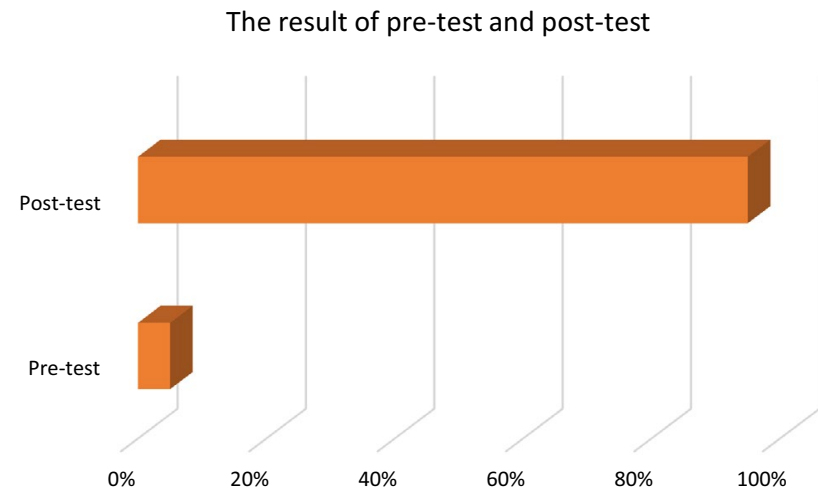

Fig. 15 The results of pre-test and post-test

E. The Result of Pre-test and Post-test
Before starting to learn multiplication using this application, a multiplication test with 20 questions was taken from children, which showed that on average they were able to answer only $5 \%$ of the questions by chance. After 10 days that the children had used this application, the same test was repeated and concluded that the children were able to answer $95 \%$ of the questions correctly. Figure 15 shows the result of pre-test and post-test use of this application.

D. Measuring the Validity of the Application

The validation process was done by six people consisting of one psychologist, one programmer, and four teachers from Bahaar kindergarten. The average rating of validators $1,2,3,4,5$, and 6 was 4.3, 4.6, 4.5, 4.9, 4.7, and 4.6, respectively. The average number of evaluations for the six validators was 4.6 (out of 5), which means that it was very valid. Therefore, based on the recapitulation 
Table 2 Measuring the validity of this application

\begin{tabular}{lllllll}
\hline Aspects & \multicolumn{7}{l}{ Validators } & & & \\
\cline { 2 - 7 } & 1 & 2 & 3 & 4 & 5 & 6 \\
\hline User interface & 3.9 & 5 & 4.1 & 4.6 & 5 & 4.8 \\
Content & 4 & 4.5 & 4.8 & 4.9 & 4.9 & 4.6 \\
Teaching method & 5 & 4.1 & 4.5 & 4.7 & 5 & 4.8 \\
Speed & 4.5 & 4.8 & 4.4 & 4.3 & 4.8 & 4.6 \\
Mean & 4.3 & 4.6 & 4.5 & 4.6 & 4.9 & 4.7 \\
Total & 4.6 & & & & & \\
Criteria & Very valid & & & & &
\end{tabular}

results, it could be concluded that this mobile application is very valid and very feasible to use in learning multiplication in kindergartens and schools. Table 2 shows the result of the validation process.

The results of testing the application among 28 preschool children showed that after 10 days, this application has increased the children's desire to learn multiplication and also has increased their learning rate to nearly $100 \%$. Also, over time, the amount of time and activity that the child spends while working with this application has increased. All of which shows the success of the TriApp in teaching multiplication to children. Also, the validity of the application was checked by six people (one psychologist and one programmer, and four teachers) and the results showed that this application is suitable for use by children and learning multiplication.

In addition, the TriApp based on the TM method can develop the creative thinking skills of preschool children $[36,37]$. They will not need any teacher or any school to learn multiplication and can learn it without paying attention to the multiply and equal sign. They learn it only by repeating the numbers and using their memory. This application is very different from the other applications and provides a good opportunity for children to learn multiplication easily and more efficiently than the old methods and applications. Because they learn multiplication as well as division before going to school. Therefore, they will have more self-confidence than other children and a positive impact, especially in the future of their education.

\section{Conclusion}

In this paper, an Android application called the Triangular App (TriApp) was designed and developed for teaching multiplication to preschool children based on the TM method designed by psychologists. With this application, children can learn multiplication before going to school and learning addition. Features of this application include the following: (1) Remembering three numbers (two numbers and the product of their multiplication) as a group and on three vertices of a triangle called Gestalt, (2) taking the test and receiving points for each correct answer, (3) learning the relationships between numbers and consequently learning division, and (4) not displaying one of these three numbers randomly in the TC section questions to increase children's learning skills. To evaluate the effectiveness of this application, it was installed on the phones of 28 preschool children's parents in Bahaar Kindergarten in Iran, and in the 10 days of using this application, their learning rate, user response, user activity, pre-test, and post-test were examined. The results of this study show that the TriApp that is a new multiplication learning application is an efficient way instead of using traditional methods to teach multiplication to preschool children remotely and has a great impact on the complete learning of preschool children even before going to school and learn addition. This application stabilizes multiplication in child's mind and improves their virtualization. Also, the designed app has encouraged children to learn and use it during the test period and then has learnt them at the highest rate. Future work can be monitoring and analyzing the children's scores (to see if a child needs further help and improvement) and providing a platform for parents or teachers to monitor their children's learning and progress. Moreover, the TriApp needs to be able to run on every operating system and platform, and every mobile device resolution. The experience gained from designing the TriApp can be applied to add more facilities, features, and different educational branches for different age groups to this app.

\section{Declarations}

Conflict of interest The authors declare that they have no conflict of interest. 


\section{References}

1. Alade F, Lauricella AR, Beaudoin-Ryan L, Wartella E. Measuring with Murray: touchscreen technology and preschoolers' STEM learning. Comput Hum Behav. 2016;62:433-41.

2. Amasha MA, Areed MF, Khairy D, Atawy SM, Alkhalaf S, Abougalala RA. Development of a Java-based Mobile application for mathematics learning. Educ Inf Technol. 2021;26(1):945-64. https://doi.org/10.1007/s10639-020-10287-0.

3. Anwar N, Kristiadi DP, Novezar FA, Tanto PA, Septha K, Ardhia P, Evan K, Chrysler A, Warnars H, Abraham J. Learning math through mobile game for primary school students. Sylwan. 2020;164(5):346-52.

4. Arnold K, Gosling J, Holmes D. The Java programming language. Boston: Addison Wesley Professional; 2005.

5. Baharum A, Wan LY, Yahya F. Mobile learning application: flipped classroom. Indones J Electr Eng Comput Sci. 2020;17(2):1084-90.

6. Berkowitz T, Schaeffer MW, Maloney EA, Peterson L, Gregor C, Levine SC, Beilock SL. Math at home adds up to achievement in school. Science. 2015;350(6257):196-8.

7. Bernacki ML, Greenea JA, Crompton H. Mobile technology, learning, and achievement Advances in understanding and measuring the role of mobile technology in education. Contemp Educ Psychol. 2020;60:101827.

8. Brian D, Jeffrey P. Dimensions of UML diagram use: a survey of practitioners. J Database Manag (JDM). 2008;19(1):1-18. https:// doi.org/10.4018/jdm.2008010101.

9. Businge J, Openja M, Kavaler D, Bainomugisha E, Khomh F, Filkov V. Studying android app popularity by cross-linking github and google play store. In: 2019 IEEE 26th international conference on software analysis, evolution and reengineering (SANER), 2019.

10. Calder N. Apps: appropriate, applicable, and appealing? In: Lowrie T, Jorgensen R, editors. Digital games and mathematics learning: potential, promises and pitfalls. Netherlands: Springer; 2015. p. $233-50$.

11. Clements DH. From exercises and tasks to problems and projects: unique contributions of computers to innovative mathematics education. J Math Behav. 2000;19:9-47.

12. Drigas A, Angelidakis P. Mobile applications within education: an overview of application paradigms in specific categories. m-learning; mobile pedagogy; education digital tools; learning design; personalized learning; augmented reality; virtual reality; standards based instruction; computer assisted instruction; intelligent tutoring systems. 2017;11(4):13. https://doi.org/10.3991/ ijim.v11i4.6589

13. Fabry DL, Higgs JR. Barriers to the effective use of technology in education: current status. J Educ Comput Res. 1997;17(4):321-39.

14. Faisal P, Kisman Z. Information and communication technology utilization effectiveness in distance education systems. Int J Eng Bus Manag. 2020;12:1847979020911872.

15. Farzad BR. Why and how toddlers should memorise the times tables: a guide for parents and teachers. CreateSpace Independent Publishing Platform. 2014.

16. Fowler M. UML distilled: a brief guide to the standard object modeling language. Boston: Addison Wesley Professional; 2004.

17. Gocheva M, Somova E, Angelova V, Kasakliev N. Types of mobile educational games for children in primary school. In: 14th International technology, education and development conference, valencia, March 2020. https://doi.org/10.21125/inted.2020.0698

18. Harahap SZ, Munandar MH, Hayati A. Design and development of mathematics and basic indonesian learning tools for early children based on android. Jurnal Mantik. 2020;4(3):2017-22.
19. Haris M, Jadoon B, Yousaf M, Khan FH. Evolution of android operating system: a review. Asia Pac J Contemp Educ Commun Technol. 2018;4(1):178-88.

20. Isman A, Dabaj F. Roles of the students and teachers in distance education. In: Proceedings of SITE 2004-society for information technology and teacher education international conference, Atlanta, GA, USA. 2004.

21. Joshi H, Brahmbhatt S, Chothani N, Ranpara D, Trivedi MA. Wireless monitoring and controlling system using android application. Int J Innov Res Sci Technol. 2016;2(9):168-73.

22. Kouhi M. Triple multiplication teaching to preschool children. Cafe Bazaar. 2017. https://cafebazaar.ir/app/com.example.zarb?l= en.

23. Kreibich J. Using SQLite. O'Reilly media. 2010.

24. Kruchten PB. The 4+ 1 view model of architecture. IEEE Softw. 1995;12(6):42-50.

25. Kwok C-P, Ng S-C, Ho C-H, Ip S-S, Kui C-WD. A mobile gamebased learning approach for motivating preschoolers and primary students in learning mathematics. In: L-K Lee, LH U, FL Wang, SKS Cheung, O Au, KC Li (Eds.) Technology in education. Innovations for Online Teaching and Learning: Singapore. 2020.

26. Lee S. Creating and using databases for android applications. Int J Database Theory Appl. 2012;5(2)

27. Lemaire P, Siegler RS. Four aspects of strategic change: Contributions to children's learning of multiplication. J Exp Psychol Gen. 1995;124(1):83-97.

28. Liu C, Hwang G-J. Roles and research trends of touchscreen mobile devices in early childhood education: review of journal publications from 2010 to 2019 based on the technology-enhanced learning model. Interact Learn Environ. 2021. https://doi.org/10. 1080/10494820.2020.1855210.

29. Means B. Technology and education change: focus on student learning. J Res Technol Educ. 2010;42(3):285-307.

30. Narkuzieva G. Modern trends in educational psychology and psychology of education. Sci Educ. 2020;1 (Special Issue 2)

31. Nikolopoulou K. Preschool teachers' practices of ICTsupported early language and mathematics. Creat Educ. 2020;11(10):2038-52.

32. Ostrin GE, Wainer SS. Elementary arithmetic. Ann Pure Appl Logic. 2005;133(1-3):275-92.

33. Pang H, Jiang L, Yang L, Yue K. Research of android smart phone surveillance system. In: 2010 international conference on computer design and applications. 2010.

34. Papadakis S, Kalogiannakis M, Zaranis N. Teaching mathematics with mobile devices and the realistic mathematical education (RME) approach in kindergarten. Adv Mob Learn Educ Res. 2021;1(1):5-18.

35. Pierce BC. Types and programming languages. MIT Press; 2002.

36. Retnawati H, Djidu H, Kartianom A, Anazifa RD. Teachers' knowledge about higher-order thinking skills and its learning strategy. Prob Educ Cent. 2018;76(2):215.

37. Rudyanto H, Ghufron A, Hartono H. Use of integrated mobile application with realistic mathematics education: a study to develop elementary students' creative thinking ability. 2019.

38. Salomon G, Almog T. Educational psychology and technology: a matter of reciprocal relations. Teach Coll Rec. 1998;100(1):222-41.

39. Stamatios P (2020) Apps to promote computational thinking concepts and coding skills in children of preschool and pre-primary school age. In: P Stamatios, K Michail (Eds.) Mobile learning applications in early childhood education (pp 101-121). IGI Global. https://doi.org/10.4018/978-1-7998-1486-3.ch006

40. Thai NTT, Wever BD, Valcke M. The impact of a flipped classroom design on learning performance in higher education: looking for the best "blend" of lectures and guiding questions with feedback. Comput Educ. 2017;107:113-26. 
41. Vogel L. Eclipse rich client platform. Lars Vogel. 2015.

42. Wei X, Cheng IL, Chen NS, et al. Effect of the flipped classroom on the mathematics performance of middle school students. Educ Tech Res Dev. 2020;68:1461-84.

43. Westwood PW. Commonsense methods for children with special educational needs. Routledge; 2007.

44. Yabut ER, Jamis MN, Manuel RE, Fabito BS. Empowering elementary schools on learning math: a development of gamified educational mobile application for grade 3 students. In: 2019 IEEE 11th international conference on humanoid, nanotechnology, information technology, communication and control, environment, and management (HNICEM), Laoag, Philippines, 2019

45. Zainuddin Z, Halili SH. Flipped classroom research and trends from different fields of study. Int Rev Res Open Distrib Learn. 2016;17(3):313-40.

Publisher's Note Springer Nature remains neutral with regard to jurisdictional claims in published maps and institutional affiliations. 